\title{
Revamping Mathematics Education: An Active Learning through Lab Activities
}

\author{
Dr .Jai Shankar Prasad Yadav \\ M.Sc (Maths), M.Ed; Ph.D (Education) \\ Jawahar Navoday Vidyalaya Wafapurarma,P.O-Sirsabiran, Vaishali,Bihar
}

\begin{abstract}
Active learning is a form of learning that requires student to reflect and apply in solving problems. It is more students centric and often involves peer learning. Today revamping of mathematics education is the major requirement for all kinds of development of the nation so it is essential demand that mathematics education should be provided to all type of students of the country; in which maths lab activities playing important role for revamping mathematics education. Mathematic laboratory is a part of formative assessment in form of activities and project.
\end{abstract}

\section{Introduction:}

Learning is the central theme of Educational Psychology. Active learning is learning which engages and challenges children and young people's thinking using real life and imaginary situations .It takes full advantages of the opportunities for learning, like spontaneous activities, planned and purposeful activities, investigating and exploring maths lab activities, focused teaching -learning. In other words active learning is experiential, mindfulness, and engaging. Though it can be explore a set of learning experiences that would be more effective and interesting, and more suitable for enrichment of mathematics education. Teacher always try to give maximum learning experience to the learner in the class room. In the present scenario teacher play critical role in the teaching learning process. Teacher teaches mathematics of same topic, same content to the all student in the class room or in mathematics laboratory; some of the active learner doing very well but few passive learner not up to mark. Another insight from neuroscience research is the surprising finding that learning is a highly individualised process - after hearing the same set of facts every student create activity his/her own meaning and a unique set of memories ,based on his/ her own beliefs and activeness. In other words, information cannot simply be transmitted passively from one mind to another, like say we can a music file, since mathematics, music and meditation are identical. Research also shows that passive teacher centric instruction does little to develop problem solving skill. Active student can support successful student through their imagination, creativity, task and getting together books, and notes studying, reviewing, and recapitulating. Students with learning difficulties' in mathematics are generally understood to be those student who require extra assistant with mathematics due their lack of ,or failure to use ,mathematical knowledge and skills .In some schools, this term is used to describe students who are performing below ,or well below ,the average level of students of their age (Van Kraayenoord \& Elkins,2004; Louden et ,2000) . Wastwood (2003) makes a distinction between students with learning difficulties and the much smaller proportion of student (3\%) with learning disabilities in mathematics, some time called dyscalculia. These students exhibit chronic problem in mastering the basic skills in mathematics, and their difficulties cannot be traced to any lack of intelligence, sensory impairment, cultural or linguistic disadvantage or inadequate teaching."Between 10 and 30 percent of primary student have difficulty learning mathematics ( Rohl et ai..,2000).Active learning is in short, anything that student do in class room other than merely passively listening to an instructor's lecture. This includes everything from listening practice which helps the students to absorb what they hear ,to start writing exercises in which student react to lecture or chalk and talk material to complex group exercise in which student apply course material to real life. Situation /or to new problem (Paulson,Faust).Mathematical games, making, charts model, quiz is a brainstorming activity in which students are asked to write the information about learnt concepts in form of the diagram. 


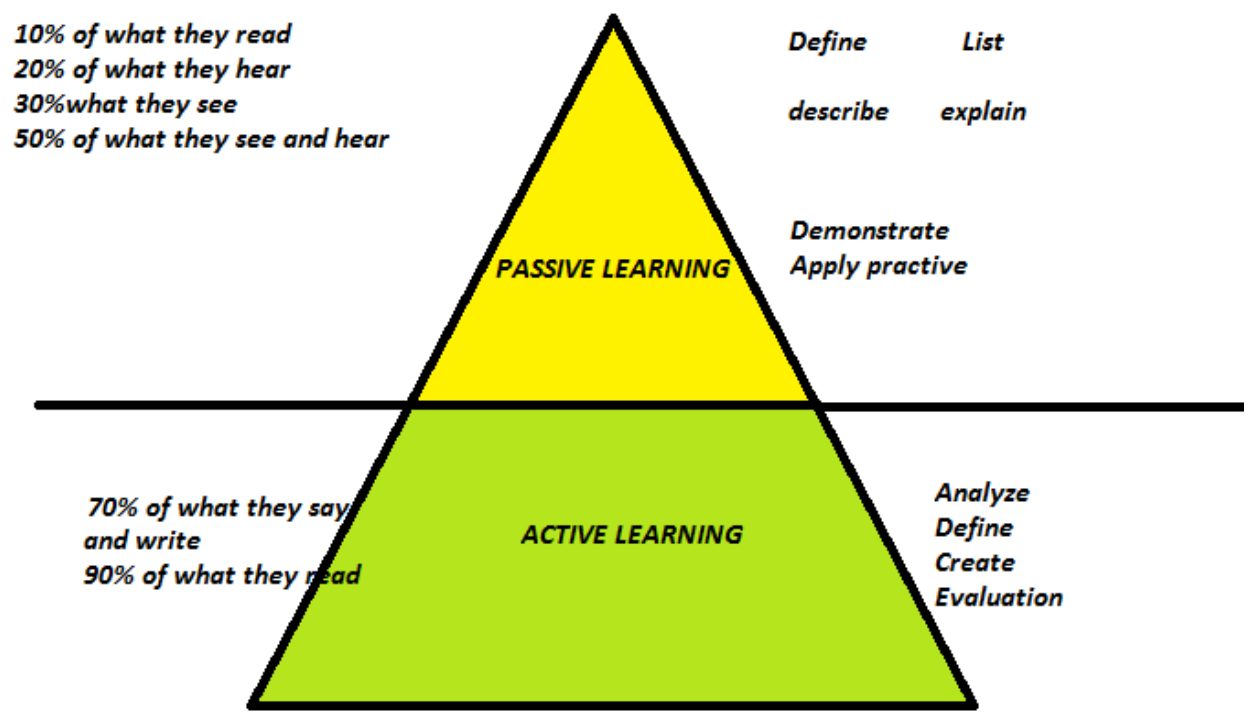

An active peer learning model is also now being adopted by high school; quick learners of mathematics can help their fellow student slow learners individually. We can say about active learning: What I hear, I forget, what I see,I remember; what I do,I understand. Singh, R.D (1992) discussed the relative merits of teaching Mathematics through computer assisted - instruction and conventional method of teaching through computer. S.N. (1977) stated that the few innovations in the field of Mathematics education and he find as follows - There existed curriculum Kapur, J.N. (1997) found only 23 departments of mathematical education out of more than 100 such departments have produced any thesis on Mathematics education in the period of 1988-1992 as per $5^{\text {th }}$ survey of educational research. Kapur, J.N. (1997) emphasizing on Mathematics education, said "Mathematics education is probably the most important area concerned with school education and its importance is vital for the development of science and technology in India. We spend hundreds of crores of rupees on teaching Mathematics in India, yet we spend very little on research on mathematical education". The empirical references available in the field of Mathematics education goes back to 1980's in Desai, H.G. (1973), Sinha D.K. (1976), Wanchoo, V.N. and Sharma, H. (1974), Gosain, K.K. (1977), Patel C.B. (1975), Lalithamma K.N. (1975), Gayen A.K., Nand P.B. and others (1961), Gupta, S.K. (1974), Tiwari S.K. (1985), Pratap D. (1982), Yadav P.S. (1984), Bhattacharya M, (1986) etc. observed that factors. Dutta A (1986) said that "To try out experimentally teaching method (go through lab disabilities in the area under study. Yadav M.S. (1984), Giri development and evolution principles well formulated, applied and found. PRACTICAL IN SCHOOL SUBJECTS INCLUDING MATHEMATICS.

Experimentation in innovative programme should be continued at Indian National level as well as at state level under the circular of national curriculum framework for elementary and secondary education (1988), NCFSE (2000), NCF (2005), and there result of experimentation with new materials in other developed (USA, UK etc.) and developing countries should be used in selecting strategy for tackling problems of innovation such as Maths Lab implementation in secondary and higher secondary course.

\section{Objective of the study}

1 To try out experimentally teaching methods which would prevent development of learning disabilities in the area under Study.

2.To estimate the extent of usefulness of mathematics laboratory in teaching and active learning process.

\section{Design of the study}

The present piece of research is qualitative and quantitative type of research. In planning and execution it is mainly survey types of research. This survey research encompasses the three types of CBSE schools i.e. Kendriya Vidyalayas, Navodaya Vidyalayas and CBSE affiliated private schools.

A total 30 senior secondary schools were selected by stratified random sampling 10 each from K.V., J.N.V. and CBSE affiliated schools.

Sample Size: 
Total No. of schools $=30$

Total No. of Teachers $=60$

No. of Principal/Vice-principal $=30$

Total No. of students $=480$

Table -01

\begin{tabular}{|c|c|c|c|c|c|c|c|c|c|c|}
\hline K.V. & 1 & 6 & 5 & 10 & 3 & 2 & 4 & 9 & 7 & 7 \\
\hline J.N.V. & 3 & 5 & 8 & 4 & 7 & 10 & 2 & 1 & 6 & 9 \\
\hline $\begin{array}{c}\text { CBSE } \\
\text { affiliated } \\
\text { schools }\end{array}$ & 6 & 4 & 9 & 8 & 1 & 2 & 3 & 10 & 5 & 7 \\
\hline
\end{tabular}

Let $R_{1}, R_{2}$ and $R_{3}$ denotes the rank given to Kendriya Vidyalaya, Jawahar Navodaya Vidyalaya and CBSE private schools respectively and let $\mathrm{i}, \mathrm{j}$ and $\mathrm{k}$ are denoted by KV, NV and PVA CBSE. After applying the obtained data to the formula given above, the results were obtained which are presented in Table 01 .

Results of Rank correlation coefficient on status of Maths Lab in three types of schools Table - 02

\begin{tabular}{|c|c|c|c|c|c|c|c|c|}
\hline 10, K.V. $\left(R_{1}\right)$ & $\begin{array}{c}10, \\
\text { J.N.V. } \\
\left(\mathbf{R}_{2}\right)\end{array}$ & $\begin{array}{c}\text { 10, Private } \\
\text { CBSE } \\
\text { Affiliated } \\
\text { Schools }\left(\mathrm{R}_{3}\right) \\
\end{array}$ & $\begin{array}{c}\mathbf{d}_{12}= \\
\mathbf{R}_{1}-\mathbf{R}_{2}\end{array}$ & $\begin{array}{c}\mathbf{d}_{13}= \\
\mathbf{R}_{1}-\mathbf{R}_{3}\end{array}$ & $\begin{array}{c}\mathbf{d}_{23}= \\
\mathbf{R}_{2}-\mathbf{R}_{3}\end{array}$ & $d_{12}^{2}$ & $d_{13}{ }^{2}$ & $d_{23}{ }^{2}$ \\
\hline 1 & 3 & 6 & -2 & -5 & -3 & 4 & 25 & 9 \\
\hline 6 & 5 & 4 & 1 & 2 & 1 & 1 & 4 & 1 \\
\hline 5 & 8 & 9 & -3 & -4 & -1 & 9 & 16 & 1 \\
\hline 10 & 4 & 8 & 6 & 2 & -4 & 36 & 4 & 16 \\
\hline 3 & 7 & 1 & -4 & 2 & 6 & 16 & 4 & 36 \\
\hline 2 & 10 & 2 & -8 & 0 & 8 & 64 & 0 & 64 \\
\hline 4 & 2 & 3 & 2 & 1 & -1 & 4 & 1 & 1 \\
\hline 9 & 1 & 10 & 8 & -1 & 9 & 64 & 1 & 81 \\
\hline 7 & 6 & 5 & 1 & 2 & 1 & 1 & 4 & 1 \\
\hline 8 & 9 & 7 & -1 & 1 & 2 & 1 & 1 & 4 \\
\hline & & & $\sum \mathrm{d}_{12}=0$ & $\sum \mathrm{d}_{13}=0$ & $\sum \mathrm{d}_{23}=0$ & $\begin{array}{c}\sum \mathrm{d}_{12}^{2}= \\
200\end{array}$ & $\begin{array}{c}\sum \mathrm{d}_{13}{ }^{2}= \\
60\end{array}$ & $\sum \mathrm{d}_{22}=214$ \\
\hline
\end{tabular}

Number of schools $=10$ from each category

$$
\therefore \mathrm{n}=10
$$

Rank Correction coefficients:

$$
\begin{aligned}
& \rho_{12} \quad=1-\frac{6 \sum \mathrm{d}_{12}{ }^{2}}{\mathrm{n}\left(\mathrm{n}^{2}-1\right)}=1-\frac{6 \times 200}{10 \times 99}=\frac{-7}{33}=-0.2121 \\
& \rho_{13} \quad=1-\frac{6 \sum \mathrm{d}_{13}{ }^{2}}{\mathrm{n}\left(\mathrm{n}^{2}-1\right)}=1-\frac{6 \times 60}{10 \times 99}=\frac{7}{11}=0.6363 \\
& \rho_{23} \quad=1-\frac{6 \sum \mathrm{d}_{23}{ }^{2}}{\mathrm{n}\left(\mathrm{n}^{2}-1\right)}=1-\frac{6 \times 214}{10 \times 99}=\frac{-49}{165}=-0.2970
\end{aligned}
$$

Among the above three correlation coefficient the KV is yielding the highest and the two others are having negative values, it may be inferred that in the case of KVs and PSA CBSE there is no positive thinking about Math Lab. In these two cases much more has to be done.

Various researchers also evaluated research gaps in the area of educational assessment like Menzel, E.W (1950), Harper, A.E, Jr (1960), Mitra, S.K (1961), Kumar, K. (1974, 1979, 1991), Kulkarni, S.S and Phuham, B.N (1988). They reviewed Indian studies, upto 1988 in the area of psychological and educational assessment. Chitnis, S and Velaskar, P (1988) examined the qualitative aspect of the then prevailing situation in Maharashtra. Learning is an active search for meaning by the learner constructive knowledge rather than passively receive it, shaping as well as being shaped by experience. 


\section{References}

[1]. Buch, M.B (1991), Chief Editor, Fourth Survey of Research in Education, 1983-1988, Volume - I, II, N.C.E.R.T., New

[2]. Courant Richard Robins Herbert, What is Mathematics? Fourth impression, 2009, Oxford University Press, YMCA Library Building, Jai Singh Road, New Delhi - 110001

[3]. Gloria Stillman ,Merrilyn Goos and Collen Vale (2008) Teaching Secondry school Mathema 362- Publisher :Allen \& Unwin 83 Alexander Street,Cross Nest NSW 2065 Australia.

[4]. Kapur, J.N. (1997), Fifth Survey of Educational Research, Page-8 \& 370, 1988-1992; Publisher N.C.E.R.T., New Delhi.

[5]. Singh Hukum, Ramavtar, Singh V.P. (2005), A Handbook for designing Mathematics laboratory in schools, Page No. 1-5, N.C.E.R.T., New Delhi.

[6]. w.w.w.maths.lab.com.in

[7]. The Hindu National News Paper page no.13, Dated on $27^{\text {th }}$ Feb 2014.

[8]. Yadav J.S.P. (2013) Status of Maths Lab : An Evaluative Study, Psycho- Lingua, ISSN 0377-3132 ;44(2):184-188 PsychoLinguistics Association 0f India( PLAI) 6/5,H.I.G Flats, Sanjay Place Agra-282002

[9]. Yadav J.S.P(2013),Mathematics Laboratory :Philosophical background, ISSN 0378-1003 ,44(2) :212-215, Editor Singh R P. Indian Journal of Psychometric and Education(IJPE) Patna ,Publisher :Indian Psychometric and Educational Research Association, Raman Tower Sanjay place, Agra-2

[10]. Yadav J.S.P.Yadav (2013) Vishwamanisha ISSN-2321-4074 volume 2-3 page no 208-210

[11]. Yadav J.S.P (2013) Makrand Majari ISSN-2321-4066 volume 2-3 page no 196-197

[12]. W.W.W.Active learning .com 